\title{
'De primeiro, a gente lembrava...' - Comunicação e interação de moradores do Assentamento Itapuí com o Movimento Sem Terra*
}

\author{
Catarina Teresa Farias Oliveira** \\ Denise Cogo****
}

\section{Resumo}

O artigo analisa as interações comunicacionais vivenciadas no contexto do Movimento Sem Terra (MST), buscando compreender como moradores de um assentamento em particular - o Itapuí- RS - mantêm e (re) atualizam sua experiência com o Movimento, por meio de um conjunto de processos comunicacionais dinamizados interna e externamente às vivências do assentamento. As reflexões teóricas fundamentam-se nos estudos culturais e de recepção com ênfase nas noções de cotidiano, experiência, identidade e memória. A metodologia, de caráter etnográfico, constituiu-se de visitas regulares com observações sistemática e pesquisa documental no cotidiano do assentamento e de realização de entrevistas antropológicas com seus moradores. Os resultados apontam que as interações dos assentados com o MST são constituídas na articulação de processos comunicacionais socioculturais não mediados pelas mídias (festas, eventos comemorativos do movimento etc.), e processos midiatizados em que assume relevância a presença da mídia de caráter comercial. Palavras chave: Comunicação. Interação. Movimento Sem Terra. Identidades. Experiência.

* Versão revisada de texto apresentado no Grupo de Pesquisa Comunicação para a Cidadania no XXXIV Congresso Brasileiro de Ciências da Comunicação, realizado em Recife de 2 a 6 de setembro de 2011.

** Professora doutora em Sociologia da Universidade Estadual do Ceará (UECE), Fortaleza-CE, Brasil, e Professora do Programa de Pós-Graduação em Comunicação, Departamento de Comunicação, Centro de Ciências da Informação, Universidade Federal do Ceará (UFC). Coordenadora do grupo Midia, Cultura e Política na UFC. Email: catarinaoliveira30@gmail.com

*** Professora doutora do Programa de Pós-Graduação em Ciências da Comunicação, Faculdade de Comunicação, UNISINOS, São Leopoldo-RS, Brasil, onde coordena o grupo de pesquisa Mídia, Cultura e Cidadania. Pesquisadora do CNPq.E-mail: denisecogo@uol.com.br 


\section{'We used to remember...' - communication and interaction between Itapuí Settlement residents and the 'Movimento Sem Terra' (Landless Movement) \\ Abstract}

This article analyses communication interaction practices amongst members of the Movimento Sem Terra (Landless Movement) - MST, in order to understand how residents of a particular MST settlement in Itapuí, RS, keep and (re)update their experiences in the movement through internal and external communicational processes. The analysis is based on Cultural Studies and Reception Studies with emphasis on the notions of daily life, experience, identity and memory. Our ethnographic methodological construction included documental research, as well as regular visits and systematic observation of the settlement's daily life. Results indicate that residents' interactions are constructed through both sociocultural processes not mediated through media like local parties and other MST celebrations and other sociocultural processes in which mediation of commercial media is relevant.

Keywords: Communication. Interactions. Landless Mouvement. Identities. Experience.

\section{'En un principio, nos venía a la memoria...' - Comunicación e interacción de los residentes del asentamiento Itapuí con el Movimiento Sin Tierra}

\section{Resumen}

El artículo analiza las interacciones comunicacionales vivenciadas en el contexto del Movimiento Sin Tierra (MST), buscando comprender cómo los residentes de un asentamiento en particular - el Itapuí-RS - mantienen y (re)actualizan su experiencia con el movimiento a través de un conjunto de procesos comunicacionales dinamizando tanto interna como externamente sus vivencias en el asentamiento. En términos teóricos, las reflexiones se basan en los estudios culturales y de recepción, y en relación a ellos, las nociones de lo cotidiano, experiencia, identidad y memoria. La metodología, de carácter etnográfico, se constituyó en función de visitas periódicas y observaciones sistemáticas de investigación documental en lo cotidiano del asentamiento y de entrevistas antropológicas con sus residentes. Los resultados apuntan a que las interacciones de los residentes con el Movimiento Sin Tierra son constituidas en la articulación de procesos comunicacionales socioculturales no mediados por los medios de comunicación (fiestas, eventos conmemorativos del movimiento etc.) y por procesos mediatizados en los cuales asume relevancia la presencia de los medios de naturaleza comercial.

Palabras clave: Comunicación. Interacción. Movimiento Sin Tierra. Identidades. Experiencia. 


\section{Introdução}

Comunicação tem sido uma dimensão preponderante na
trajetória de organização do Movimento dos Trabalhadores
Rurais Sem Terra, MST desde 1984, quando o Jornal Sem Terra foi criado oficialmente pelo movimento, até esta segunda década do século 21. Martins e Nunes (2011) têm sugerido que o movimento teria operado um deslocamento de um modo marcadamente instrumental de assumir a Comunicação para um entendimento do caráter estratégico e processual dessa Comunicação. A afirmação das autoras aparece mais como uma realidade do MST evidenciada em espaços associados eminentemente à elaboração de políticas comunicacionais do movimento do que como uma prática observada na realidade dos assentamentos, conforme pudemos constatar na pesquisa realizada no assentamento Itapuí-RS cujos resultados relatamos nesse texto.

Como decorrência das próprias lutas empreendidas pelos Sem Terra nessas últimas décadas, percebemos que há diferenças entre três instâncias que se interligam e compõem o MST - as instâncias de movimento, acampamento e assentamento - no contexto dos quais os processos e projetos comunicacionais do MST assumem especificidades e podem se materializar ou se expressar de modo diferenciado. Em linhas gerais, podemos dizer que o movimento compõe a instância de organização, mobilização e ação mais genérica do MST, com atuações públicas; o acampamento é resultado das ocupações empreendidas pelo movimento; e o assentamento, a dimensão de conquista e permanência na terra.

Partindo dessa diferenciação, propomos pensar os reflexos das políticas comunicacionais do MST em seus assentamentos perguntando: como moradores de um assentamento do MST mantêm e (re) atualizam sua experiência com o Movimento através de um conjunto de interações comunicacionais socioculturais algumas das quais mediadas pelos meios de Comunicação, que se dinamizam no cotidiano de suas vivências internas e externas ao assentamento? Para a análise dessas interações, adotamos um percurso meto- 
dológico constituído de uma abordagem de caráter etnográfica no assentamento Itapuí, localizado no município de Nova Santa Rita, no estado do Rio Grande do Sul, a $35 \mathrm{~km}$ da capital, Porto Alegre. A etnografia abrangeu visitas regulares com observações sistemáticas, pesquisa documental no cotidiano do assentamento e a realização de entrevistas antropológicas com seus moradores no período de outubro de 2010 a junho de 2011.

\section{MST e Comunicação: duas óticas de abordagem}

No percurso de construção da pesquisa que gerou esse texto, nos foi útil verificar, inicialmente, a existência de um conjunto de reflexões acadêmicas sobre a Comunicação no MST que ajudam a entender diferentes óticas de abordagem da inter-relação entre Movimento Sem Terra e Comunicação e ao mesmo tempo identificar, entre esses estudos, a ausência da abordagem específica que aqui propomos. Em nosso mapeamento, encontramos pesquisas que contemplam dois eixos, o primeiro deles centrado na relação do movimento com a chamada mídia comercial $^{1}$ e na problematização de como esses meios narram os acontecimentos em que o MST está envolvido (BERGER, 2006; VARGAS, 2006). Em uma de suas pesquisas sobre a Comunicação e o MST, Berger (2006) analisa a cobertura de diversos Meios de Comunicação em torno do episódio ocorrido no Dia Internacional da Mulher e narrado pela mídia como "danos" a uma Unidade da Aracruz Celulose no Rio Grande do Sul causados por militantes do MST

\footnotetext{
${ }^{1}$ Utilizamos o termo mídia comercial para fazer referência ao universo dos Meios de Comunicação de Massa, mas reconhecemos a limitação do termo para distinguir um tipo de experiência que se contrapõe às Mídias Alternativas e Comunitárias no cenário atual de fragmentação e de intensificação de fluxos e redes comunicacionais, especialmente a partir da presença da internet. Não desconsideramos, ainda, as distinções internas ao universo da mídia comercial e/ou massiva que, nos casos das pesquisas já realizadas sobre o MST aqui referidas, focalizam predominantemente a relação entre movimento e revistas e jornais impressos de grande circulação e pertencentes a grandes e tradicionais corporações midiáticas como, por exemplo, Zero Hora, vinculado à Rede Brasil Sul de Comunicações, e revista Veja, vinculada ao Grupo Abril.
} 
e do Movimento das Mulheres Camponesas. A exemplo de outros trabalhos similares, Berger (2006) evidencia a homogeneização no enquadramento da cobertura sobre o episódio em todos os veículos estudados, bem como a ausência de fontes dissonantes na difusão da informação. Não se limitando a dicotomizar a relação entre mídia comercial e MST, as pesquisas nesse primeiro eixo constatam que, apesar de desigual, essa relação foi importante para o despertar do Movimento para a importância estratégica da mídia comercial para a construção e difusão da visibilidade pública do MST (BERGER, 2006; VARGAS, 2009).

Um segundo eixo das pesquisas que mapeamos analisa as estratégias comunicacionais do MST por meio da construção de mídias próprias que visam à construção de uma autoimagem do movimento no âmbito das lutas simbólicas em que está inserido. (NUNES, MENEZES, CARVALHO, 2009). Essas pesquisas apontam para uma dimensão dominante de criminalização da imagem do movimento na mídia comercial que, em certo sentido, pode ter contribuído para a Comunicação assumir papel estratégico para o MST, conduzindo o movimento a investir na produção de mídias próprias. Outro ângulo de análise sobre as mídias produzidas pelo MST está presente em investigações sobre as rádios comunitárias instaladas em assentamentos² (GUINDANI, 2010; MARTINS, 2009). Essas pesquisas têm problematizado as práticas da Comunicação de caráter comunitário. Esse mapeamento dos dois ângulos de análise contemplados nas pesquisas sobre o MST ajudou a compor um conjunto de percepções acerca de uma visão de Comunicação do Movimento centralizada na produção de notícias para a sociedade. Nesse sentido, concordamos com Oliveira (2011) quando observa que estruturas comunicacionais do MST "apresentam uma função de Comunicação intrínseca, que faz parte de sua organização e de sua forma de atuação política no espaço público da sociedade" (OLIVEIRA, 2011, p.15), mas que, no entanto, segundo o autor, revelam "limites na integração entre as

\footnotetext{
${ }^{2}$ A coordenação de Assentamentos da Região do Rio Grande do Sul, em Porto Alegre, não dispõe de registros dos números de rádios comunitárias em assentamentos no país.
} 
estruturas de Comunicação no que tange à inserção das demandas comunicacionais dos acampados, caracterizando, portanto, um processo comunicacional de dialogia parcial, com predominância de elementos difusionistas" (OLIVEIRA, 2011, p.15). Reconhecendo esses limites levantados por Oliveira (2011), mas sem reduzir o valor estratégico da Comunicação do MST, procuramos perceber nuances dessas estruturas comunicacionais nas inter-relações do MST com a realidade dos assentamentos.

\section{Opções teórico-metodológicas para estudo da Comunicação nos assentamentos}

As pesquisas sobre Comunicação do MST no cotidiano dos assentamentos, conforme os estudos que revisitamos, têm demandado abordagens de campo de caráter qualitativo ${ }^{3}$, como aquelas oriundas das tradições teórico-metodológicas dos estudos culturais e, no âmbito delas, as pesquisas de recepção, às quais se vincula também a investigação que dá origem a esse texto (MARTÍN-BARBERO, 1987; COGO, 2009; ESCOSTEGUY, 2006; JOHNSON, 1999; JACKS, 2010). Na dimensão política de "conhecimento útil", Johnson (1999) se preocupa em afirmar a necessidade dos pesquisadores dos estudos culturais britânicos priorizarem a aproximação, contato e interação com o cotidiano e a realidade "concreta" das culturas. Esse compromisso "político-empírico" está presente entre os pesquisadores tanto da linha inglesa como da vertente latino-americana dos estudos culturais. Se na tradição inglesa isso pode ser evidenciado nas investigações sobre práticas de resistências das chamadas subculturas (ESCOSTEGUY, 2006, p.141), na América Latina, essa preocupação aparece de modo mais claro em pesquisas que buscam compreender experiências de Comunicação popular e alternativa dos movimentos sociais. Nesse âmbito, segundo Cogo (2009), através de sua vinculação aos movimentos populares, os

\footnotetext{
${ }^{3}$ Diferente das investigações que analisam o MST a partir de conteúdos midiáticos, quando problematizam a abordagem que a mídia comercial faz sobre a atuação do MST ou quando analisam as narrativas da Revista e do Jornal Sem Terra, bem como do site do Movimento (www.mst.org.br).
} 
EC ${ }^{4}$ abrem possibilidades para a legitimação de um pensamento científico autônomo latino-americano frente à predominância de matrizes de pensamentos norte-americanas e europeias.

No que se refere especificamente aos estudos de recepção, Jacks (2010) identifica, no contexto brasileiro, o crescimento dessa tradição empírica com um enfoque voltado para contextos socioculturais particulares. Ao fazer a análise de um universo de 102 dissertações e teses sobre recepção, defendidas entre 2000 e 2005, a autora registra 31 trabalhos com abordagem sociocultural em contraponto aos 32 trabalhos que adotaram essa perspectiva de análise em toda a década de 90. Para Jacks (2010, p.161), "esta perspectiva problematizou e enfrentou melhor a complexidade da relação das audiências com os meios de Comunicação quando adentra no universo cotidiano e examina as práticas culturais dos sujeitos sociais em questão".

Como instância de dinamização da cultura, os estudos de recepção colaboram, ainda, com nossa pesquisa para o entendimento do cotidiano dos assentamentos como espaço que inclui conflito e ao mesmo tempo resistência; lugar não apenas de reprodução, mas igualmente de produção de sentidos e práticas; instância em que também a política assume outra configuração deixando de ser entendida não apenas associada à dimensão macro e formal das instituições para ser compreendida em micros contextos de sociabilidade (COGO, 2009). Esse viés teórico-metodológico, predominante nas pesquisas de recepção, nos fizeram perceber igualmente que, no caso do MST, as investigações que adotaram essa tradição reflexiva têm conseguido se aproximar do Movimento a partir de uma perspectiva mais interna e abranger suas duas outras instâncias: acampamentos e assentamentos. A metodologia de nossa pesquisa foi também construída a partir de uma perspectiva etnográfica em que a incursão no cotidiano do assentamento Itapuí-RS nos levou a constituir um percurso de reflexão em que buscamos articular,

\footnotetext{
${ }^{4}$ Cabe mencionar que utilizamos a terminologia "estudos culturais latino-americanos" cientes de que não tem sido amplamente adotada no contexto acadêmico da América Latina para fazer referência às pesquisas em Comunicação relacionada aos movimentos sociais.
} 
em uma perspectiva latino-americana, a Comunicação produzida pelos movimentos sociais com a tradição das pesquisas de recepção. Além disso, a própria realidade comunicacional do assentamento nos conduziu à articulação de dois posicionamentos que demarcam o desenvolvimento dos estudos de recepção na América Latina: (1) as pesquisas que buscam estudar a recepção a partir de processos socioculturais e comunicacionais em que não estão necessariamente implicados os meios de Comunicação e (2) as pesquisas que se voltam à análise da recepção dos meios de Comunicação ou às práticas de recepção midiática. (COGO, 2009, p.1-2).

Essas duas perspectivas dos estudos de recepção requerem que pensemos a pertinência da noção de experiência para o entendimento das interações comunicacionais mediadas e não mediadas pelas mídias no cotidiano dos moradores do assentamento Itapuí-RS com o Movimento Sem Terra. O alerta sobre a suposta crise da experiência como um valor da modernidade nos chega pelo pensamento de Benjamin (1994) e nos chama a atenção sobre as transformações dessa experiência na contemporaneidade. "Quem encontra ainda pessoas que saibam contar histórias como elas devem ser contadas? Que moribundos dizem hoje palavras tão duráveis que possam ser transmitidas como um anel de geração em geração?", indaga o autor ao se voltar para o que denomina de pobreza da experiência no marco de um conjunto de reflexões que o elabora em um contexto de forte difusão das tecnologias e de emergência da técnica na modernidade (BENJAMIN, 1994, p.114). Ao enfatizar que a "nova forma de miséria surgiu com esse monstruoso desenvolvimento da técnica sobrepondo-se aos homens" (BENJAMIM, 1994, p.115), o autor aponta para o surgimento de uma nova forma de Comunicação, que nomeia informação, e à qual associa a essa crise da experiência. ${ }^{5}$ Em perspectiva similar de preocupação com a centralidade da técnica, Silverstone (2002), reconhece igualmente a onipresença da mídia na constituição de nossa experiência contemporânea. Contudo, embora o autor

\footnotetext{
${ }^{5}$ Existiria assim uma associação das percepções críticas de Benjamin sobre o desenvolvimento dos Meios de Comunicação e de seu padrão informacional assumido no capitalismo.
} 
assuma que a mídia é central na textura da experiência social na contemporaneidade, pergunta não apenas sobre o papel da mídia na formação de experiência, mas também e principalmente sobre o papel da experiência na formação da mídia.

Essas reflexões orientam nosso entendimento sobre as experiências com o MST que se constituem entre os assentados de Itapuí a partir de interações comunicacionais que podem contar ou não com a presença das mídias e que se compõem de um conjunto de processos de identificações e rememorações que estabelecem com o Movimento. Em termos identitários, cabe lembrar que a trajetória do MST é demarcada pela criação de um repertório de simbologias, como hino, bandeira, cruz, música etc., que se materializam e difundem em materialidades diversas (como bonés, camisetas, lenços, canetas, chaveiros, agendas, cartazes), assim como nas mídias comerciais e naquelas produzidas pelo movimento. Essa simbologia abrange, ainda, a celebração de um calendário de eventos coletivos como o Dia Mundial de Luta Camponesa ${ }^{6}$, manifestações em praça pública no dia do trabalhador rural, marchas do MST a Brasília, colaborando para a permanência e reatualização de processos de identificação dos integrantes do MST com o Movimento. Trata-se de estratégias de reconhecimento e identificação utilizadas pelo MST que se aproximam daquelas encontradas em processos referentes à construção da identidade nacional.

Ao refletir sobre identidades culturais e os processos de identificação, Hall (1998, p.50) nos remete à noção de que as "culturas nacionais são compostas não apenas de instituições culturais, mas também de símbolos e representações", assinalando enfaticamente que "uma cultura nacional é um discurso, um modo de construir

\footnotetext{
${ }^{6} \mathrm{O}$ dia 17 de abril foi instituído pela conferência da Via Campesina Internacional como Dia Mundial de Luta Camponesa, em homenagem aos sem terra que foram mortos no massacre de Eldorado dos Carajás, no Pará. Em todo mundo acontecem manifestações nesta data. Na mesma época, por iniciativa da ex-senadora Marina Silva, o então presidente Fernando Henrique Cardoso assinou um decreto reconhecendo 17 de abril como o Dia Nacional de Luta pela Reforma Agrária. Ver http:// www.mst.org.br/node/2955. A Via Campesina é uma organização internacional de camponeses fundada em 1992. Conferir em http://www.viacampesina.org/sp
} 
sentidos que influencia e organiza tanto nossas ações quanto a concepção que temos de nós mesmos" (HALL, 1998, p.50). Na perspectiva de uma comunidade imaginada criada historicamente, os sentidos de identificação e pertença a uma identidade nacional são forjados, segundo HALL (1998) pelas memórias do passado, pelo desejo de viver em conjunto e pelo desejo de perpetuação da herança. Nas ações do MST, a criação da simbologia anteriormente referida tem sido uma estratégia de constituição de identificações entre os integrantes do Movimento. Entretanto, em nossa observação no assentamento Itapuí, constatamos que, a exemplo de todos os demais processos de identificação, aqueles vivenciados pelos moradores do assentamento em relação ao MST são provisórios, variáveis e conflitivos (HALL, 1998), com a especificidade, porém, de serem nutridos por uma dimensão de experiência em que os assentados já não estão mais tão fortemente vinculados às práticas e lutas do Movimento e, principalmente, após 25 anos de conquista da terra, terem que renegociar sua identidade de "sem terra”. Nessa perspectiva, as dinâmicas de rememoração e reatualização dos vínculos e identificações com o Movimento emergem como uma dimensão preponderante no cotidiano do assentamento, quando consideramos na perspectiva proposta por Traverso (2007, p.22), que, em função de seu caráter subjetivo, assim como as identidades, a memória não é fixa, mas está em constante mutação como produto da compreensão de que "o tempo erosiona e debilita a lembrança”. No trabalho de campo, foi possível evidenciar o fluxo de tensões que envolvem os processos de rememoração e reatualização dos vínculos dos assentados com o MST, incluindo aqueles provocados pela própria presença das pesquisadoras no campo, conforme veremos mais adiante.

\section{Trajetória do assentamento Itapuí: origens e processos comunicacionais}

A pesquisa, de caráter etnográfico, foi realizada no assentamento Itapuí, localizado no município de Nova Santa Rita, no Rio Grande do Sul, a $35 \mathrm{~km}$ da capital, Porto Alegre, contexto local do 
qual nos aproximamos a partir da indicação de lideranças do $\mathrm{MST}^{7}$. O trabalho de campo desenvolveu-se em duas etapas. Uma primeira fase, centrada na observação mais geral, na aproximação com os seus moradores e em pesquisa documental no assentamento ${ }^{8}$ e, se estendeu de outubro a dezembro de 2010. Em uma segunda etapa, desenvolvida entre março e junho de 2011, foram realizadas visitas semanais, com algumas estadas prolongadas no assentamento ${ }^{9}$, e a realização de entrevistas antropológicas (GUBER, 2004) ${ }^{10}$. Nesses dois períodos, observamos e entrevistamos oito famílias, com as quais convivemos e acompanhamos em ocasiões como almoços, cafés, assistência à televisão ou simplesmente por meio da permanência e conversas informais em suas casas. Participamos ainda de outras atividades como aniversário da escola, palestras, missas, almoços, churrascos e jantares na casa de assentados etc. Nessas incursões sistemáticas, buscamos nos aproximar também de sujeitos que encontramos em outros espaços, tais como ônibus, ruas, missas etc. Como procedimento metodológico complementar, coletamos fotografias cedidas pelos moradores e captamos imagens em vídeo de diferentes espaços e atividades do assentamento.

\footnotetext{
${ }^{7}$ Ver mais dados e localização detalhada do assentamento em http://pt.wikipedia. org/wiki/Nova_Santa_Rita_(Rio_Grande_do_Sul)

${ }^{8}$ A pesquisa documental esteve centrada especialmente na coleta de fotografias de álbuns das famílias de assentados/as, bem como a exemplares de jornais e revistas, de arquivos pessoais dos assentados/as que nos foram cedidos pelos entrevistados/as. As fotografias registram momentos de interação entre os moradores como missas, aniversários do assentamento, formaturas na escola etc. Estas cenas do cotidiano registraram as interações vividas pelos assentados/as na trajetória de 25 anos do Itapuí.

${ }^{9} \mathrm{Na}$ primeira etapa, as entradas em campo foram semanais com duração de até três dias e pernoite em campo. Na segunda fase, permanecemos períodos de dois dias por semana também com pernoite em campo. A maior parte das incursões em campo estiveram a cargo de Catarina Farias Oliveira, umas das coautoras desse texto, como atividade de pesquisa de seu estágio de pós-doutorado desenvolvido no Programa de Pós-Graduação em Ciências da Comunicação da Unisinos-RS e supervisionado pela outra coautora do trabalho, Denise Cogo.

${ }^{10}$ Enquanto a entrevista mais formal é geralmente marcada e nasce de um acordo prévio, a entrevista antropológica se gera no marco da convivência cotidiana do pesquisador com os atores sociais no contexto do trabalho de campo (GUBER, 2004).
} 
O assentamento Itapuí possui extensão total de 1.177,6 hectares, onde se instalaram 68 famílias oriundas de uma pequena parcela da fazenda Anoni ${ }^{11}$, um dos mais antigos e maiores acampamentos do MST localizado no norte do estado do Rio Grande do Sul, entre os municípios de Pontão e Sarandi. A maioria das 1,5 mil famílias e sete mil pessoas instaladas em Anoni conviveu nesse acampamento por oito anos, entre 1985 e 1993. A saída da fazenda Anoni para Itapuí ocorreu em 1987, de forma fragmentada. Em 1987, chegaram a Itapuí as primeiras 15 famílias da fazenda Anoni para se estabeleceram como acampados da fazenda Meridional, conforme era denominado, nessa época, o espaço que abrigaria, posteriormente, o assentamento Itapuí. Seis meses depois, um segundo grupo de 42 famílias procedentes da fazenda Anoni chegou a Itapuí após ter permanecido em torno de seis meses na cidade de Pelotas ${ }^{12}$ com a promessa, que acabou não sendo cumprida, de serem assentadas. Por fim, outras duas famílias chegaram em 1993 oriundas da fazenda Anoni. Antes da efetivação do assentamento em 1988, as famílias acamparam durante um ano nos portões da fazenda Meridional até conseguirem ser assentadas em casas que construíram com a madeira dos eucaliptos encontrados na própria terra onde se instalaram. Após cinco anos, cada família recebeu 12,6 hectares de terra, optando, a partir de então, pelo trabalho individual ou coletivo. Itapuí é formado por duas áreas interligadas entre si por estradas de terra de jurisdição municipal e distantes $2 \mathrm{~km}$ uma da outra. Se considerados apenas os assentados originários, na parte de cima de Itapuí, vivem 27 famílias e, na parte de baixo, moram outras 41 famílias.

Na história do assentamento, a Comunicação tem sido vivenciada não apenas vinculada diretamente às mídias, seja as de caráter comercial ou as produzidas pelo MST. Dinâmicas de sociabilidade como festas, promoção de missas, reuniões de grupos, jantares, churrascos, jogos de futebol, dentre outros,

${ }^{11} \mathrm{O}$ acampamento da fazenda Anoni é hoje um assentamento com o mesmo nome - Assentamento Anoni.

${ }^{12}$ Uma das principais cidades da região sul do Estado do Rio Grande do Sul, situada a $250 \mathrm{~km}$ de Porto Alegre. 
vêm constituindo processos comunicacionais importantes para o fortalecimento dos laços de convivência entre os assentados e de sua identificação com a história do MST e com a origem do Itapuí. Dentre essas dinâmicas, também se destacam, nos relatos dos assentados, a construção, em 1990, da escola Nova Sociedade, criada a partir de um processo de luta do qual participaram pais, filhos e dirigentes do MST, e a construção das comunidades católicas Nossa Senhora Aparecida ${ }^{13}$, e Nossa Senhora da Libertação ${ }^{14}$. Nessas duas últimas, são realizadas missas, jantares e outros eventos, embora durante nossa pesquisa de campo o prédio da comunidade Nossa Senhora Aparecida tenha estado sem o telhado e, em razão disso, com seu funcionamento desativado. Ouvimos depoimentos de moradores que rememoraram os tempos áureos de realização de bailes no espaço da comunidade.

No período de dois anos em que o prédio da Nossa Senhora Aparecida esteve fechado ${ }^{15}$, a escola Nova Sociedade cedeu seu espaço para as atividades da comunidade, principalmente para a realização das celebrações que geralmente ocorrem aos sábados pela manhã com a presença de um padre e de poucas pessoas. $\mathrm{Na}$ única vez em que acompanhamos a celebração, 17 pessoas compareceram ao evento, muitas das quais pertenciam à mesma família ${ }^{16}$.

Nas nossas visitas iniciais ao assentamento, a exposição, nas paredes da escola, de vários símbolos caros ao MST - como quadros de Paulo Freire, Che Guevara, bandeiras do MST - nos sugeriam a constituição da escola como espaço comunicacional de forte presença no assentamento. Aos poucos, fomos percebendo, contudo, as fragilidades atuais sobre os sentidos de sua atuação para os moradores. Segundo alguns assentados, em etapas anteriores, a escola representou um lugar importante de identificação com o assentamento, por meio, por exemplo, da realização, em

\footnotetext{
${ }^{13}$ Localizada no Itapuí de cima, em frente à escola Nova Sociedade.

${ }^{14}$ Situada no Itapuí de baixo.

${ }^{15}$ Ao término da pesquisa, o prédio estava sendo recuperado e já se encontrava com um telhado novo.

${ }^{16}$ Acompanhamos uma celebração e conversamos sobre eventos católicos com Tânia, moradora que nos hospedava em sua casa durante o trabalho de campo.
} 
parceria com os pais, de acampamentos com os alunos. "De primeiro a gente lembrava aqui no acampamento da escola, agora daqui pra cá, não fizeram mais acampamento na escola ${ }^{17}\left(\right.$ Selma $^{18}$, assentada Itapuí, 53 anos)". Os professores da escola atribuem esse enfraquecimento da atuação da escola ao fato da instituição já não receber muitos filhos de assentados e que, em função disso, a responsabilidade da realização de atividades como acampamentos juvenis recairia integralmente sob a escola, especialmente no que se refere aos cuidados dos jovens no período noturno ${ }^{19}$. No aniversário de 20 anos da Escola Nova Sociedade, em 2010, estivemos presente e observamos um número pequeno de pessoas na festa. Sobre os processos organizativos, os moradores lembram que, no início do assentamento, havia mais mobilização, fazendo referência à diminuição do trabalho em grupo orientado à produção agrícola e à realização de reuniões. Dificuldades que não encobrem os esforços, conforme pudemos perceber, de criação de iniciativas coletivas como cooperativas, grupos de plantação etc., alguns dos quais ainda em funcionamento. "De primeiro, uns 10 anos atrás tinha mais, era bem entrosado, tinha grupos de famílias. E a gente fazia os protestos e ia bastante gente. Depois foi diminuindo um pouco, mas ainda tem, não é tanto, mas tem (Tânia, assentada Itapuí, 65 anos)”.

\section{Processos comunicacionais e experiências de interação com o MST}

A rememoração da história com o MST tem sido construída através de festas, jantares em comunidade e da comemoração do aniversário do assentamento, embora tenha havido anos, como em 2008 e 2009, em que o aniversário não foi festejado. Fotografias que coletamos dos arquivos pessoais dos assentados registram missas, aniversários do assentamento, formaturas na escola, dentre

\footnotetext{
${ }^{17}$ Há quatro anos que a escola já não organiza mais os acampamentos que eram realizados anualmente no feriado do dia 12 de outubro com a duração de três dias. ${ }^{18}$ Os nomes dos entrevistados foram alterados por questões éticas.

${ }^{19}$ Os professores mencionaram, ainda, a complexidade da juventude atual como um dos fatores que dificultam a realização de atividades como acampamentos.
} 
outros momentos de interação e confraternização entre os moradores. Em muitas fotografias, a bandeira do MST e a cor vermelha são elementos que servem de decoração das festas na escola.

Durante a pesquisa, percebemos que, além desses processos comunicacionais vividos no próprio assentamento, outro modo da vinculação e (re) atualização da experiência com o MST é vivenciado a partir da participação de assentados em ações do Movimento. Há diversos registros também fotográficos em que assentados aparecem em atos políticos e de mobilização em companhia de seus filhos e netos. Paralelo às dinâmicas comunicacionais citadas, a pesquisa no assentamento revelou que as interações com o MST ocorrem por meio de processos comunicacionais diretamente ligados a outras mídias, e não apenas à fotografia, que circulam entre os moradores dentro e fora do assentamento. Nesses processos, contudo, as mídias do MST parecem participar pouco da constituição de dinâmicas de identificação que os assentados mantêm com o Movimento. Na verdade, evidências do trabalho de campo indicam que, inclusive, as mídias comerciais podem ser mais efetivas nesse processo. Em uma das estadias mais prolongadas no assentamento ${ }^{20}$, fizemos um levantamento na biblioteca da escola e constatamos que a revista e o Jornal Sem Terra, embora tivessem circulado ali, sugeriam não ter sido muito usados ou demandados pelos moradores, tendo em vista a ausência de edições do jornal posteriores a $2008^{21}$, assim como a presença de um único número do jornal Sem Terrinha, também datado de 2008. Outro indicativo dessa fraca presença veio após a entrevista com Tania ${ }^{22}$, assentada de 65 anos, que afirmou não conhecer a Revista Sem Terra e ter tido pouco contato com o Jornal produzido pelo movimento, cujos exemplares chegaram a ser trazidos, em algumas ocasiões, pelo seu marido. $\mathrm{O}$ episódio vivenciado com a

\footnotetext{
${ }^{20}$ No feriado de 15 de novembro de 2010, passamos cinco dias no assentamento e acompanhamos os preparativos para a festa de aniversário da escola.

${ }^{21}$ Contabilizamos a presença de 15 números e 52 exemplares do Jornal Sem Terra, publicados entre 1997 e 2008 e disponíveis na biblioteca da escola.

22 As primeiras constatações vieram com o levantamento feito na escola Nova Sociedade e a partir da realização das primeiras entrevistas.
} 
entrevistada nos chama atenção para o fato de que, ao estarem ausentes do assentamento, as mídias do MST estariam deixando de ter incidência no reconhecimento e fortalecimento, junto aos assentados, de suas experiências, memórias e processos vividos junto ao Movimento. Os assentados do Itapuí, conforme pudemos perceber, não tiveram no acampamento da fazenda Anoni, onde viveram anteriormente, aprendizados homogêneos sobre a trajetória histórica e atuação do Movimento e, em função disso, precisaram constituir e atualizar vínculos com o MST a partir da vivência no assentamento. Nessa mesma perspectiva, outro assentado, Julio ${ }^{23}$, jovem de 20 anos, aluno da escola Nova Sociedade e da escola de formação do MST em Pontão no Rio Grande do Sul, afirmou que tomou conhecimento do site do Movimento quando necessitou fazer matrícula em um curso de graduação da Terra ${ }^{24}$, na cidade de Pelotas, em 2010. Em contrapartida ${ }^{25}$, em seu depoimento, o jovem ressalta o conhecimento que obteve sobre o Movimento por meio de filmes que assistiu e atividades de que participou no contexto da escola do Pontão, o que parece ter lhe possibilitado uma interação que ainda não havia experimentado com a história e memória do Movimento.

No decorrer do trabalho de campo, um episódio em particular e de forte repercussão midiática que colocava em foco a atuação do MST se tornou recorrente em relatos de moradores do assentamento. Os assentados aludiam ao dia 8 de março de 2006 quando 1,8 mil mulheres da Via Campesina ocuparam o viveiro hortoflorestal da empresa Aracruz Celulose, em Barra do Ribeiro, município que fica cerca de duas horas de Porto Alegre. Na ação, divulgada pela mídia comercial, as mulheres teriam destruído estufas e bandejas de mudas de eucalipto. Alguns assentados que entrevistamos nos relataram esse fato, questionando a ação do MST e se referindo à

${ }^{23} \mathrm{O}$ jovem é filho de um dos coordenadores da Comunidade Nossa Senhora Aparecida

${ }^{24}$ Denominação dada pelos MST a cursos de graduação em diversas áreas mantidos pelo Movimento em parceria com universidades.

${ }^{25}$ Filmes que tratam da trajetória do MST, embora não sejam produzidos pelo Movimento. 
midiatização do acontecimento em meios massivos que haviam utilizado como fonte principal para se informarem sobre o episódio ${ }^{26}$. Edina, de 67 anos, que mantém um forte vínculo com o movimento $^{27}$, ressaltou o questionamento dos filhos sobre esse tipo de ação do MST: "vamos supor, esses manifestos que eles fazem, que eles vão que eles quebram, que eles fazem aquilo, os meus filhos não gostam. Eles gostariam que fosse na santa paz tudo (...). Aquela vez que eles foram num sei aonde que arrancaram todos os eucaliptos. Meu Deus do céu, eles ficaram loucos (Edina, assentada Itapuí, 67 anos)". Sobre o mesmo episódio, ouvimos também o relato de Leda, assentada de 53 anos de idade que participou diretamente do episódio da Aracruz. Leda não é oriunda da fazenda Anoni como seu esposo, Dante, filho de assentado, mas ela já esteve em outro acampamento. Leda nos contou de sua militância conjuntamente com Janete, outra moradora do assentamento, e de sua participação em diversos eventos de mobilização do MST como ocupação do McDonald's, caminhada de mulheres, e a própria ocupação na Aracruz. "Eles invertem muito, que nem naquela ação que eu te contei que nos fomos lá dos eucaliptos. Lá nós vimos na nossa frente os brigadianos ${ }^{28}$. E nós vendo o brigadiano pegar aquelas folhinhas, amarrar sequinhas e botar dentro do papel pra dizer que era droga e saiu na televisão que foi achado droga. (...) (Leda, assentada Itapuí, 53 anos)". Em outra conversa durante a pesquisa de campo, perguntamos sobre o episódio dos eucaliptos a Tania e a Selma, ambas consideradas atuantes nas atividades do MST, e, portanto, com experiência e memória com o Movimento supostamente fortalecidas. "A televisão mostrava bem o que eles fizeram, destruíram as mudas né [será que ela não distorceu nada?] Não [responde Tania] (Tania, assentada Itapuí, 65 anos)”.

Entre os moradores que mencionaram o episódio da Aracruz, apenas Leda questionou a cobertura da mídia com base em sua

\footnotetext{
${ }^{26}$ Os assentados citaram principalmente a cobertura televisiva.

27 Dona Edina sempre participou de atividades do MST em Porto Alegre mas, recentemente, deixou de participar devido a problemas de saúde.

${ }^{28}$ Termo utilizado no Rio Grande do Sul para designar os policiais militares que atuam em âmbito estadual.
} 
experiência direta no episódio. Os demais assentados tinham a mídia comercial como fonte preponderante de informação sobre o acontecimento. Embora tivessem uma atuação junto às atividades do MST, esta não parecia ser suficiente para contextualizar a ação do Movimento e colocar em xeque modos de narrar o episódio por parte da mídia massiva. Nesse caso, mesmo aqueles com mais experiência na militância não chegaram a expressar algum questionamento sobre a cobertura da mídia, inclusive Selma, esposa de Ari Baioneta, assentado que foi espancado pela polícia no acampamento da Anoni.

\section{Considerações finais}

Percebemos que a interação dos assentados com o MST é construída em dimensões que estão sendo vivenciadas em seu cotidiano e articuladas, tanto em processos comunicacionais socioculturais não mediados pelos meios de Comunicação (festas, eventos comemorativos, atuação nas atividades do MST, dentre outros), quanto a partir de processos midiatizados (relações com narrativas e produtos midiáticos comerciais e não comerciais). Narrativas que circulam e são apropriadas em um contexto de vivências tanto de sujeitos mais identificados com o MST e com trajetórias mais estreitamente vinculadas ao Movimento quanto de sujeitos que experimentam trajetórias mais frágeis de interação com o MST. É no marco desse cenário sociocultural e político que vislumbramos que uma maior presença, nesse contexto, de mídias do MST e de outras ações comunicacionais do Movimento poderiam funcionar como contrapontos nessa trama de construção de sentidos, operando particularmente nos vínculos e identificações dos assentados com o Movimento e ao mesmo tempo colaborando na pluralização de narrativas criminalizadoras sobre as ações mobilizadoras do MST propostas por algumas mídias comerciais. Por fim, sem a pretensão de idealizar os processos de identificação dos assentados com o MST, reconhecemos sua importância para o fortalecimento de um projeto sociopolítico que o Movimento constrói num contexto não raramente adverso às suas propostas. 


\section{Referências}

BENJAMIN, Walter. Magia e técnica, arte e política: ensaios sobre literatura e história da cultura. 7.ed. São Paulo: Brasiliense, 1994 (Obras escolhidas; v. $1)$.

BERGER, Christa. O caso Aracruz. Do fato ao acontecimento jornalístico (um outro, o mesmo). UNIrevista, São Leopoldo, v. 1, n. 3, p.1-15, jul. 2006.

COGO, Denise. Los Estudios de Recepción en América Latina: perspectivas teórico-metodológicas. Portal de la Comunicación. Instituto de la Comunicación (InCOM) de la UAB (Universidade Autónoma de Barcelona), Barcelona, 2009. Disponível em: < http://www.portalcomunicacion.com:80/esp/n_aab_ lec_1.asp?id_llico=48> Acesso em: 09 abr. 2009.

FEITOSA, Sara. Televisão e juventude Sem Terra, mediações e modos de subjetivação. 2007. 171 f. Dissertação (Mestrado em Educação) - Programa de Pós-Graduação em Educação, UFRGS, Porto Alegre.

GUINDANI, Joel F. Políticas comunicacionais e a prática radiofônica na sociedade em midiatização: um estudo sobre os documentos de Comunicação do Movimento Sem Terra, MST e Rádio Terra Livre FM. 2010. 157f. Dissertação (Mestrado em Ciências da Comunicação) - Programa de Pós-Graduação em Ciências da Comunicação, Unisinos

GUBER, Rosana. El salvaje metropolitano. Reconstrucción del conocimiento social en el trabajo de campo. Buenos Aires, Paidós, 2004.

HALL, Stuart. Identidades culturais na pós-modernidade. Rio de Janeiro: DP, 1998.

JACKS, Nilda et al. Pesquisa de recepção, empírica por natureza. In: BRAGA, José Luis; LOPES, Maria Immacolata Vassalo de; MARTINO, Luis C. (Orgs.). Pesquisa empírica em Comunicação. São Paulo: Paulus, 2010. p.161-181.

JOHNSON, Richard; ESCOSTEGUY, Ana Carolina; SCHULMAN, Norma.

O que é, afinal, estudos culturais? Belo Horizonte: Autêntica, 1999. p.7-131.

MARTIN-BARBERO, Jesús. De los medios a las mediaciones. Mexico: Gustavo Gilli, 1987.

MARTINS, Helena. Onde só vento se semeava outrora - Comunicação: espaço de luta política - Análise da rádio 25 de maio FM, produzida pelo Movimento dos Trabalhadores Rurais Sem Terra”. 2009. Monografia (Graduação 
em Comunicação Social) - Faculdade de Comunicação, Universidade Federal do Ceará, Fortaleza.

MARTINS, Helena; NUNES, Marcia Vidal. Das idéias que se fazem gestos: sensibilização, formação e produção de novas ações comunicativas. In: XX ENCONTRO ANUAL DA COMPÓS, 2011. Porto Alegre, Anais... Porto Alegre: UFRGS, 2011.

NUNES, Marcia Vidal; MENEZES, Antonio Simões; CARVALHO, André. Gurjão... Auto-imagem do MST na "Revista Sem Terra": a Guerra Simbólica através da Mídia. In: XXXII CONGRESSO BRASILEIRO DE CIÊNCIAS DA COMUNICAÇÃO. 2009. Curitiba, Anais.... Curitiba: Positivo, 2009.

OLIVEIRA, Guilherme J. Pereira Hernandes. Comunicação como elemento de mobilização política e dialogia no MST Nacional. In: IV CONGRESSO DA ASSOCIAÇÃO BRASILEIRA DE PESQUISADORES EM COMUNICAÇÃO E POLÍTICA. 2011, RJ. Anais.... RJ, 2011.

OLIVEIRA, Aline P.; MENDES, Jeferson, dos Santos. A fazenda Anoni e o papel da Igreja. Revista Semina, Londrina, UEL, v. 7, n 1, p.1-15, 2009 (publ. no $1^{\circ}$ sem. 2010).

SILVERSTONE, Roger. Por que estudar a mídia? São Paulo: Loyola, 2002.

TRAVERSO, Enzo. El pasado, instrucciones de uso - historia, memoria, politica. Barcelona/Madrid: Marcial Pons, 2007.

VARGAS, Isabel Junqueira. Ocupando manchetes: Como o MST agenda a mídia. 2006. 161f. Dissertação (Mestrado em Comunicação) - Programa de Pós-Graduação em Comunicação, UNB, Brasília. 